\title{
Measurement of melatonin in body fluids: Standards, protocols and procedures
}

\author{
Eduardo Alves de Almeida • Paolo Di Mascio • Tatsuo Harumi • D. Warren Spence • \\ Adam Moscovitch • Rüdiger Hardeland • Daniel P. Cardinali • Gregory M. Brown • \\ S. R. Pandi-Perumal
}

Received: 3 August 2010 /Accepted: 7 September 2010/Published online: 21 November 2010

(C) Springer-Verlag 2010

\begin{abstract}
Background and Purpose The circadian rhythm of melatonin in saliva or plasma, or of the melatonin metabolite 6sulfatoxymelatonin (a6MTs) in urine, is a defining feature of suprachiasmatic nucleus (SCN) function, the body's endogenous oscillatory pacemaker. The primary objective of this review is to ascertain the clinical benefits and limitations of current methodologies employed for detection and quantification of melatonin in biological fluids and tissues.

Data Identification A search of the English-language literature (Medline) and a systematic review of published articles were carried out.
\end{abstract}

E. A. de Almeida

Departamento de Química e Ciências Ambientais, IBILCE, UNESP,

Rua Cristóvão Colombo 2265,

CEP 15054-000 São José do Rio Preto, SP, Brazil

P. Di Mascio

Departamento de Bioquímica,

Instituto de Química,

USP Av. Prof. Lineu Prestes, 748,

CEP 05513-970 São Paulo, SP, Brazil

\section{T. Harumi}

Department of Anatomy,

Asahikawa Medical College,

Nishikagura, Asahikawa, Japan

D. Warren Spence

323 Brock Ave.,

Toronto, ON, Canada M6K 2M6

\section{A. Moscovitch}

Sleep and Fatigue Institute,

106 Codsell Ave,

Toronto, ON, Canada M3H 3W1
Study Selection Articles that specified both the methodology for quantifying melatonin and indicated the clinical purpose were chosen for inclusion in the review.

Data Extraction The authors critically evaluated the methodological issues associated with various tools and techniques (e.g. standards, protocols, and procedures).

Results of Data Synthesis Melatonin measurements are useful for evaluating problems related to the onset or offset of sleep and for assessing phase delays or advances of rhythms in entrained individuals. They have also become an important tool for psychiatric diagnosis, their use being recommended for phase typing in patients suffering from

R. Hardeland

Johann Friedrich Blumenbach Institute of Zoology

and Anthropology, University of Göttingen,

Göttingen, Germany

D. P. Cardinali

Departamento de Docencia e Investigación,

Facultad de Ciencias Médicas,

Pontificia Universidad Católica Argentina,

1107 Buenos Aires, Argentina

G. M. Brown

Centre for Addiction and Mental Health,

250 College Street,

Toronto, ON, Canada M5T 1R8

S. R. Pandi-Perumal ( $\square)$

Somnogen Inc,

College Street,

Toronto, ON, Canada M6H 1C5

e-mail: pandiperumal2009@gmail.com 
sleep and mood disorders. Additionally, there has been a continuous interest in the use of melatonin as a marker for neoplasms of the pineal region. Melatonin decreases such as found with aging are or post pinealectomy can cause alterations in the sleep/wake cycle. The development of sensitive and selective methods for the precise detection of melatonin in tissues and fluids has increasingly been shown to have direct relevance for clinical decision making.

Conclusions Due to melatonin's low concentration, as well as the coexistence of numerous other compounds in the blood, the routine determination of melatonin has been an analytical challenge. The available evidence indicates however that these challenges can be overcome and consequently that evaluation of melatonin's presence and activity can be an accessible and useful tool for clinical diagnosis.

Keywords Melatonin - Circadian rhythms .

Radioimmunoassay · Enzyme-linked immunoassay .

High-performance liquid chromatography · Mass

spectrometry . Capillary electrophoresis

\section{Introduction}

Melatonin ( $N$-acetyl-5-methoxytryptamine) is a compound secreted mainly by the pineal gland, but synthesized also in many other tissues and cells, including the retina [1-3], human and murine bone marrow cells [4], platelets [5], the gastrointestinal tract [6], skin [7], or lymphocytes [8]. Because of the multiplicity of sites of formation and the presence of melatonin receptors in diverse locations, melatonin appears to be a versatile physiological signal that has been found involved in the control of numerous physiologic processes $[9,10]$. In mammals, photoperiodic information is relayed through the secretion of melatonin by the pineal gland, which then acts on the brain, and the neuroendocrine system to produce adaptive changes in endocrinology, anatomy, and physiology, thus affecting sleep, reproduction, molting, immune responses, energy balance, and behavior, among others [11-14]. Moreover, melatonin exhibits direct and indirect antioxidant properties, and there is strong evidence that this compound can counteract the deleterious effects of reactive oxygen and nitrogen species in different systems [15-19].

Although numerous physiological functions have been attributed to melatonin, the mechanisms involved in such functions are frequently unclear, especially when parallel signaling pathways that are initiated via the membrane receptors $\mathrm{MT}_{1}$ or $\mathrm{MT}_{2}$ are considered, or when other melatonin binding sites are involved [20]. Therefore, further investigation at cellular and molecular levels is needed to elucidate how this compound really acts as a relevant physiological regulatory signal.
Although in vitro studies can furnish important information on the effects of melatonin in cell culture or perfused tissues, studies of the fluctuations of melatonin concentration in body fluids and tissues generally have the most relevance for understanding its function in organisms. Thus, the development of sensitive and selective methods for the precise detection of these compounds in tissues and fluids of animals has become necessary. However, due to its low concentration and the coexistence of many other endogenous compounds in blood, the determination of melatonin has been an analytical challenge. This review discusses current methodologies employed for detection and quantification of melatonin in biological fluids and tissues.

Melatonin fluctuations in organisms

In vertebrates, the chronobiologically relevant fraction of melatonin is mainly produced and released into the circulation by either the pineal gland, especially in mammals, or pineal gland plus retina, e.g., in some birds and amphibians $[21,22]$. The pineal glands of nonmammalian species are directly photosensitive while those of mammals are controlled by neuronal phototransduction pathways originating in the retina and then processed by the hypothalamic circadian pacemaker, the suprachiasmatic nucleus (SCN) [21, 23, 24]. In various birds, light influences circadian oscillators present in the pineal gland and acts additionally on neuronal pathways of retinal or hypothalamic origin modulating the gland [25-27]. The contribution of extrapineal/extraretinal melatonin to blood plasma concentrations of the hormone are either very low or, in the case of gastrointestinal origin, only episodic and without profound chronobiological significance [6].

In humans, nocturnally peaking high-amplitude oscillations of melatonin in plasma are paralleled by corresponding variations in saliva [28]. Although plasma levels are generally about ten times higher than those found in saliva, determinations of salivary melatonin can be advantageous, especially when it is preferred to avoid invasive procedures. The primary melatonin metabolite in the urine, 6-sulfatoxymelatonin, also oscillates consistently with melatonin concentration in urine, plasma, and saliva [28]. Melatonin levels in human plasma usually begin to increase between 18:00 and 20:00 h, and peak between midnight and 05:00 $\mathrm{h}$ [28-32], being followed by a rapid decrease. The duration of the nocturnal melatonin peak has been shown to be the crucial signal for encoding season [33]. However changes in the duration also occur in nonseasonal animals. For example, in the rat the duration of the melatonin increase is closely tied to the photoperiod [34]. Seasonal changes in the nocturnal peak of melatonin 
have also been widely reported with the amount of change varying between species. The nocturnal peak of pineal melatonin secretion in the Siberian hamster during the winter is two times greater than during the summer [35], while that of the European hamster shows a 10-fold increase [36]. Seasonal variations in melatonin duration and levels are also found in humans, but less prominently so. Again, the duration and amplitude of the melatonin peak is negatively correlated with the length of the photoperiod [37, 38].

Another important aspect of melatonin fluctuation in humans concerns variable environmental light intensities. It has been proposed that melatonin secretion during dark phases is greatly influenced by dim light, whereas very bright light can "mask" melatonin production [39]. Dim light can be particularly important in the circadian entrainment of rhythms. Moreover, the suppression of melatonin formation and release by nocturnal light represents a well-known phenomenon, of particular importance due to its health consequences in shift workers [40]. The photic shutoff mechanisms depend on the respective organism and may be based either on dephosphorylation of a key enzyme in melatonin biosynthesis, arylalkylamine $\mathrm{N}$-acetyltransferase (AANAT), thus preventing interaction with a 14-3-3 protein, and followed by rapid proteasomal degradation, and/or on downregulation of AANAT expression [41, 42]. Consequently, melatonin's actions are not only influenced by the phase of the light-dark cycle, but can be strongly affected by variations in light and dim light intensities. Moreover, both normal melatonin patterns and the influence of light can vary considerably between individuals, either in terms of personal characteristics [43$46]$ or as a consequence of aging or a chronic disease [4752]. Studies in siblings have indicated that some of this variation has a genetic origin [53].

The close linkage between secretion levels of melatonin and the great variations in the pacemaker processes controlling circadian and annual rhythms suggests that a causal relationship may exist in these processes. In etiological terms, changes in melatonin have been repeatedly suspected to have involvement in numerous diseases, in the susceptibility to inflammatory processes or in genetic predispositions. The health-related roles of melatonin seem to reflect a mixture of hormonal, immunomodulatory, neuromodulatory, and various types of antioxidant actions, and its efficacy in safeguarding these underlying processes is observed at very low concentrations [20]. Therefore, it seems that fluctuations in melatonin duration and levels which may appear, at first glance, to be of only minor significance, may cause, in the long run, important pathophysiological changes. Because melatonin levels are relatively low even at nighttime highly specific and sensitive methods for melatonin measurements in biological samples are essential.
Relevance of melatonin assay in pediatric neurosurgery

Since the description of validated assays for melatonin in plasma, there has been a continuous interest in the use of melatonin as a marker for neoplasms of the pineal region [54-58]. The elevated diurnal melatonin levels reported in some initial studies $[54,56]$ were not verified in later descriptions of relatively larger series of pineal region neoplasms [58]. For example, in two series of tumors that included four [59] and five pineal parenchymal neoplasms [57] only one of the patients displayed high diurnal levels of melatonin.

The best evidence on the validity of plasma melatonin assay for diagnosis of neoplasms of the pineal region was given by a recent study on 29 tumors of the pineal region, including germ cell tumors, pineal parenchymal tumors, meningiomas, and glial tumors [58]. Presurgically, the daily rhythm of plasma melatonin was suppressed in undifferentiated or invasive tumors. Postsurgically, the absence of a melatonin rhythm could be correlated with a damage of the pineal gland by surgery.

Melatonin deficiency could be the cause of a postpinealectomy syndrome that includes alteration of sleep/ wake cycle [60] and recurrent headache and depression [61]. Somnolence after pinealectomy is amenable of exogenous melatonin treatment [62] as is the daily somnolence seen among craniopharyngioma survivors, the most common extraneural tumors of the CNS in children $[63,64]$. In craniopharyngiomas the disrupted sleep pattern presumably results from dysfunction of the hypothalamic circadian pacemaker located in the SCN which suppresses the circadian rhythmicity of melatonin [65].

\section{Determination of melatonin in biological samples}

Considering its low levels an important issue of melatonin measurements is its adequate extraction from biological samples. In serum samples, melatonin can be extracted by simple liquid/liquid procedures, such as the addition of dichloromethane $(1: 1, \mathrm{v} / \mathrm{v})$. Samples are then vigorously mixed and centrifuged to obtain aqueous and organic phases. With this procedure, melatonin is retained in the dichloromethane phases that are collected and dried under nitrogen atmosphere to concentrate melatonin. This yields a satisfactory recovery rate (generally more than $70 \%$ ), and can be also applied to buffer-homogenized tissues. However, a low precision and accuracy with single liquid-liquid extractions of melatonin for high performance liquid chromatography (HPLC) coupled to fluorescence detector have been reported [66]. For multiple analyses of melatonin and its precursors or metabolites, more profound liquid-liquid extractions have been described using a combination of different solvents [67]. 
In older investigations, chloroform (trichloromethane) was mostly used for melatonin extraction and is still in use today. Although this method is effective, dichloromethane is preferred for reasons of lower toxicity. Generally, chlorinated methane should be of highest purity and protection from light and redox-active compounds is of utmost importance for avoiding formation of reactive intermediates which can destroy melatonin.

Laganà et al. [31] described an extraction procedure for serum samples through an LC-18 cartridge plus a Carbograph cartridge with a recovery ranging from 86.3 to $91.7 \%$ for 10 to $200 \mathrm{pg}$ melatonin $/ \mathrm{ml}$. Briefly, $2 \mathrm{ml}$ of serum sample is passed through an LC-18 cartridge, which is then washed with $2 \mathrm{ml}$ of water and $2 \mathrm{ml}$ of water-methanol $(90: 10, v / v)$. Thereafter, melatonin can be eluted from the column with pure methanol, dried and resuspended in an appropriate solution for analysis [68] or can be further purified by eluting with $2 \mathrm{ml}$ of water-methanol (40:60, v/v) and loading onto a Carbograph cartridge [31]. The cartridge is then washed with $10 \mathrm{ml}$ of methanol and $3 \mathrm{ml}$ of methanol-dichloromethane $(80: 20, \mathrm{v} / \mathrm{v})$, and melatonin is finally eluted with $1.5 \mathrm{ml}$ of methanol-dichloromethane $(10: 90, v / v)$. The eluate is evaporated to dryness under $N_{2}$ atmosphere and resuspended in $100 \mu \mathrm{l}$ of water-methanol $(75: 25, \mathrm{v} / \mathrm{v})$ for analyses.

Sample preparation will also depend on the method used for analysis, since the presence of other compounds in the sample can interfere with the melatonin signal. The extent of melatonin prepurification from biological samples can, in some cases, be fundamental for the sensitivity of the method used. The procedure described above allows melatonin detection with high sensitivity and without interference from other components in the sample [31]. It has been shown that homogenization in $10 \mathrm{vol}$ of ice-cold $0.1 \mathrm{M}$ perchloric acid can also represent an accurate means for melatonin determination in tissues by HPLC coupled to electrochemical or fluorescence detection [69]. In this case, the homogenate is centrifuged at $10,000 \times \mathrm{g}$ for $20 \mathrm{~min}$ at $4^{\circ} \mathrm{C}$ and the resulting supernatant can be directly injected into the HPLC system. It has also been suggested that $90 \mu \mathrm{l}$ of the supernatant fraction be mixed with $10 \mu$ of $1 \mathrm{M}$ sodium phosphate, $\mathrm{pH} 4.3$, for better resolution of peaks.

Depending on the method used, further treatment of melatonin extracts may be needed. Gas chromatographymass spectrometry (GC-MS) detection of melatonin requires sample derivatization for melatonin volatilization by, for example, the use of pentafluoropropionic anhydride or heptafluorobutyrylimidazole [70, 71]. In another approach, human plasma samples have been directly injected into and evaluated in an HPLC system with fluorescence detection without prior extraction or purification, achieving a detection limit of $1 \mathrm{ng}$ per $\mathrm{ml}$ of human plasma (4 pmol/ ml) [72]. Also, it has been reported that derivatization of melatonin with sodium carbonate and hydrogen peroxide increases sensitivity almost 10 -fold for measurement in HPLC systems coupled to fluorescence detectors [73].

Rolčik et al. [74] described a highly specific method for melatonin isolation and purification from complex biological matrices by immunoaffinity chromatography [74]. Polyclonal antibodies highly specific against melatonin were raised by Mannich synthesis [75] and used for preparation of immunoaffinity gel, with a $95 \%$ recovery rate for melatonin extraction. In these samples, melatonin concentration was determined by HPLC-mass spectrometry (HPLC-MS) with a detection limit of $10 \mathrm{fmol}$.

Regarding sample preparation for analysis by MS, the use of adequate isotopically labeled internal standards represents an important issue; this step improves quantification of the hormone and underestimation of actual levels of melatonin due to losses which might have occurred in the samples during extraction.

Finally, the correct handling and maintenance of samples is also important. Samples of melatonin should be kept constantly on ice and protected from light radiation, in order to avoid degradation. Despite its relative stability, melatonin oxidation can occur over time, including reactions with singlet oxygen. The probability of this occurrence varies, and is dependent on oxygen availability and light incidence. For sample freezing, it is recommended that samples be dried and preferentially kept under vacuum or nitrogen atmosphere.

\section{Immunoassay}

For the monitoring of melatonin in biological fluids, use of immunological methods is the most widespread method. Several commercial kits based on these methods are available for melatonin determination. Some of these methods are highly sensitive and simple to use (lower limit of detection: $0.5 \mathrm{pg} / \mathrm{ml}$ ) but may suffer from a potential risk of cross-reactivity to structurally similar compounds if melatonin is not extracted $[76,77]$.

The most crucial aspect of immunoassays is the preparation of the antiserum. Because melatonin is too small to be capable of producing antisera on its own it must be coupled to an antigenic protein. In such a conjugate the small molecular weight substance is called a hapten. The resulting antiserum binds both the protein and the hapten plus a portion of the adjacent protein. The hapten has few antigenic determinants relative to the protein. Specificity studies of antisera produced by steroid-protein conjugates have shown that antisera are not able to discriminate structural differences in the hapten that are immediately at or close to the site of coupling [78].

The choice of the hapten and conjugation reaction should therefore be determined by the type of discrimination that is required. Indolealkylamines have in common a 
ring nitrogen (position 1) and an adjacent carbon (position 2). Thus for melatonin, coupling via the position 1 or position 2 should allow resulting antisera to discriminate different indoles that are commonly found in tissues.

Studies of antisera resulting from Mannich coupling of melatonin to bovine serum albumin (BSA) have revealed that this approach leads to a highly specific melatonin antiserum as shown by cross-reactivity studies in radioimmunoassay (RIA) [76, 79-81]. To determine the locus of attachment of melatonin to protein, model reactions have been conducted and the resulting products analyzed by nuclear magnetic resonance and infrared spectroscopy [78]. The results of the study indicated that coupling was likely at position 2. Further studies were done of cross-reactivity of intermediate reaction products revealing that the highest cross-reactivity occurred with $\mathrm{C}-2$ substituted melatonin derivatives. Thus it was concluded that the methylene bridge conjugating melatonin to BSA occurred at the number 2 position of the indole molecule. This approach has been used widely for melatonin immunoassays. Recently, two different groups have used this approach for generating monoclonal antisera against melatonin [81, 82].

Coupling at the ring nitrogen using 1-( $p$-carboxybenzyl)melatonin [83] coupled to BSA as antigen [75] results in antisera that bind melatonin specifically. Melatonin-1propionic acid coupled to BSA also stimulates production of highly specific antisera. A similar approach by coupling 1-(4-carboybutyl)-melatonin to protein resulted in a highly specific RIA [84]. The melatonin derivative, 3-(3-(2acetamidoethyl)-5-methoxy indol-1-yl) propionic acid coupled to bovine gamma globulin produces a specific antiserum that has been used widely in RIA $[85,86]$. Yet another derivative $N$-[3-(2-aminoethyl)-5-methoxy indole] hemisuccinamide has been used to generate antiserum as the basis for a specific RIA [87]. Thus melatonin coupled at the $N$ position gives rise to antisera that are highly specific for melatonin as compared to other indoles.

Coupling at the side chain has also successfully produced useable melatonin antiserum. The methods used include $\mathrm{N}$ acetyl-5-methoxytryptophan coupled using carbodiimide [88, 89], succinyl-5-methoxy-tryptamine coupled to protein [90] and indomethacin coupled to protein [91]. Melatonin coupled via a diazo linkage has also been reported to produce a reasonably specific antiserum, however the sensitivity of the resulting assay was found to be low $[92,93]$.

Coupling of $N$-acetylserotonin using formaldehyde generates antiserum that binds melatonin and $\mathrm{N}$-acetylserotonin equally; cross-reactivity studies and model reactions have shown that coupling occurs at the 4th position of the molecule $[94,95]$. The resulting antiserum has been used as the basis of an RIA that required prior extraction and column chromatography to eliminate the cross-reacting indole [95].
The chief metabolite of melatonin in urine, 6sulfatoxymelatonin (6- hydroxymelatonin sulfate) has also been measured by immunologic means. The antiserum typically used for this assay is generated by use of the Mannich reaction and is highly specific [94, 96]. Antisera produced using these approaches have been used extensively not only for RIA, but also for immunohistochemistry and for enzyme-linked immunoassays (ELISA).

\section{Radioimmunoassay}

The principle of RIA method for melatonin measurement is that a known amount of radioactive melatonin $\left(2-\mathrm{I}^{125}\right.$ iodomelatonin or ${ }^{3} \mathrm{H}$-melatonin) is mixed with a fixed amount of antibody raised against melatonin. Increasing concentrations of unlabeled melatonin are added to the mixture, which will compete with labeled melatonin causing its displacement from the antibody. Free labeled melatonin is then separated from remaining antibody-bound radioactive melatonin and radioactivity is measured. As the concentration of unlabeled melatonin increases in the mixture, competition for the antibodies also increases and bound labeled melatonin decreases. A calibration curve constructed from known amounts of labeled and unlabeled melatonin allows the determination of unknown melatonin concentrations in biological samples.

Fraser et al. [97] described a protocol for melatonin measurement by RIA in plasma that has been adopted by several researchers, some with slight modifications. Briefly, $200 \mu \mathrm{l}$ of 1000 -fold diluted antibody is added to $500 \mu \mathrm{l}$ of solutions containing different amount of melatonin standard ( 2.5 to $250.0 \mathrm{pg}$ ). The solution is vortexed and kept at room temperature for $30 \mathrm{~min} .{ }^{3} \mathrm{H}$-melatonin is added to the tubes $(100 \mu \mathrm{l}, 4,000 \mathrm{cpm})$, mixed, and kept at $4^{\circ} \mathrm{C}$ for $18 \mathrm{~h}$. Then, $0.5 \mathrm{ml}$ of Dextran-coated charcoal solution $(0.1 \mathrm{~g}$ of dextran 75 plus $10 \mathrm{~g}$ of charcoal per $500 \mathrm{ml}$ of buffer) is added and the solution is centrifuged for $15 \mathrm{~min}$ at $1,500 \times g$ and $4^{\circ} \mathrm{C}$, in order to separate the antibody-bound melatonin from the free fraction. The supernatant fraction is finally decanted into $10 \mathrm{ml}$ of scintillation fluid and radioactivity is counted on a beta scintillator counter [97].

Several variations in RIA methods have been described, by using different antibodies (as noted above), by changing ${ }^{3} \mathrm{H}$-melatonin to $2-\mathrm{I}^{125}$-iodomelatonin, or by altering the separation procedure. In general, because of its higher specific activity $2-\mathrm{I}^{125}$-iodomelatonin allows a lower detection limit thus allowing the use of a smaller amount of sample. The concentration of melatonin during daylight can be as low as 0.2 to $0.3 \mathrm{fM}$ [74]. This could be especially important if measurements are not preceded by melatonin purification. However, ${ }^{125} \mathrm{I}$ is more prone to nonspecific binding so that some determinations can be faulty. 
Sieghart et al. [68] reported that prior melatonin purification from plasma using reversed-phase column chromatography greatly reduces the problems of crossreactivity. Moreover, Rolčik et al. [74] used immunoaffinity chromatography employing specific antisera to process samples prior to HPLC-MS analysis. Nonetheless, it should be recognized that even a weak cross-reactivity can be a problem if the cross-reacting molecule is present in large quantities. Thus independent validation of the procedure is essential when a different matrix is assayed.

One example of such a different matrix is saliva for which several RIAs have been described [98-101]. To obtain saliva, different methods have been used, from chewing gum, chewing on cotton swabs, or using commercial apparatus. Again, extraction is usually essential especially since levels in saliva are about $40 \%$ of those in plasma. Saliva is particularly useful if repeated sampling is required: for example to characterize the full $24 \mathrm{~h}$ rhythm of melatonin or to determine the dim light melatonin onset (DLMO), a measure that has been shown to be very useful in studies on circadian rhythmicity in sleep disorders $[30,102,103]$.

Several variants of the time-consuming charcoal separation procedure have been developed and successfully applied. In the so-called scintillation proximity assay, the melatonin antibody is bound to a secondary antibody (e.g., antisheep) attached to scintillator-containing microbeads ("fluomicrospheres") [104]. This relatively convenient procedure depends, however, usually on the commercial availability of suitable fluomicrospheres, since preparation and standardization of such beads is too time-consuming for the average laboratory. In the proximity assay, bound radioactivity is detected directly by the scintillator system of the microspheres. For physical and geometrical reasons, such a system has to have a lower scintillation efficiency than a homogeneous scintillation cocktail. However, this procedure has other advantages. Apart from being more rapid, the system is less affected by nonspecific binding (values close to background) such as occur in the charcoal procedure, has a better reproducibility and shows a much lower assay drift upon repetitive measurements (proximity assay: about $10 \%$ change within $84 \mathrm{~h}$; charcoal method: about $25 \%$ over the same period) [104]. Other variants include separation using a double antibody procedure [77] and ammonium sulfate precipitation [34].

Considerable interest has also been shown in the major urinary metabolite of melatonin, 6-sulfatoxymelatonin [96]. The 24-h pattern of excretion of the metabolite accurately reflects the pattern of melatonin in blood [105, 106]. RIAs for this substance are available and have been useful in assessing pineal function in various conditions $[49,50$, 107-110].
Fig. 1 Chromatogram of melatonin standard (2 pmol; a) and melatonin extracted from $2 \mathrm{ml}$ of a plasma sample (b), by HPLC with coulometric electrochemical detector

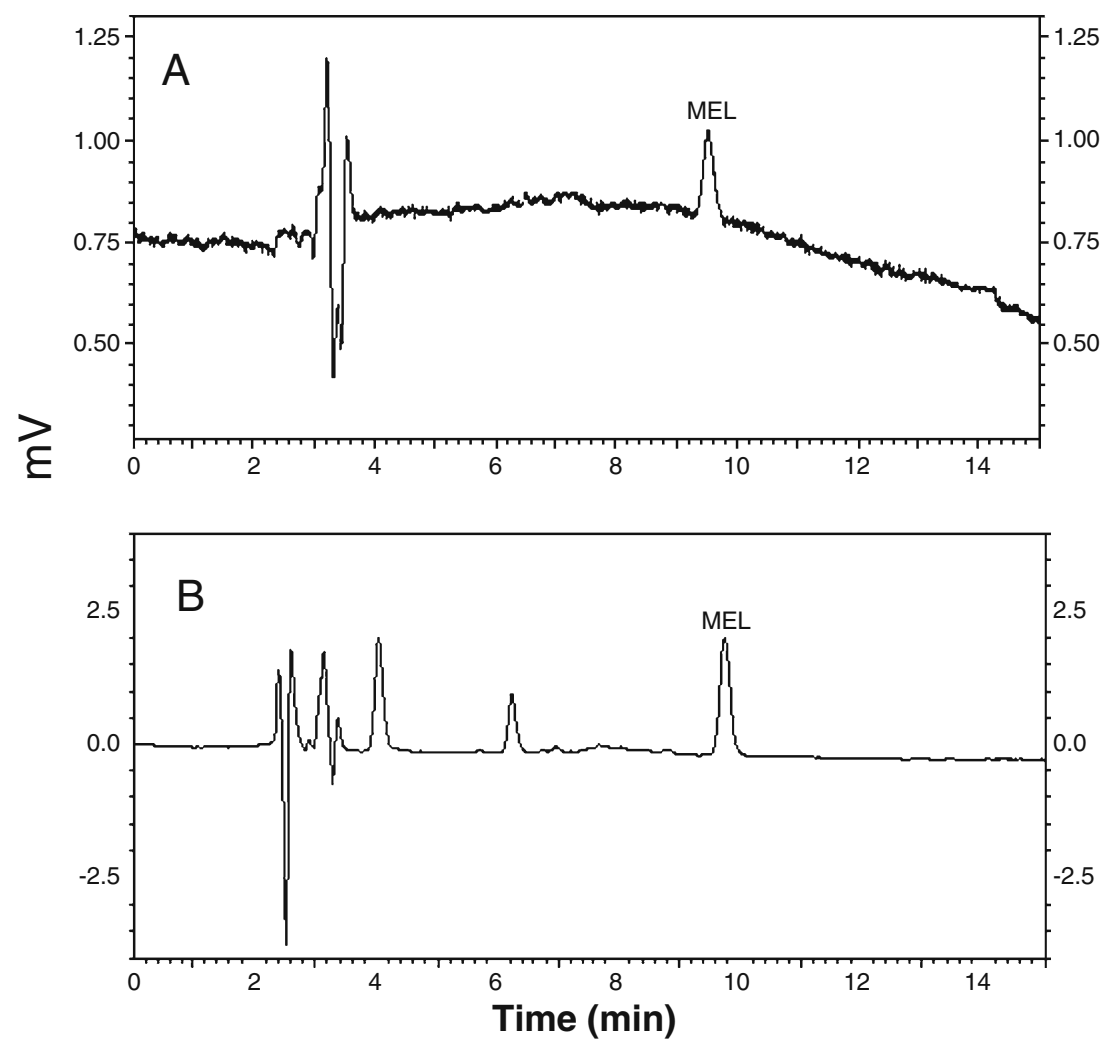


Fig. 2 Synthesis of labeled $\mathrm{D}_{3}$ melatonin for its use as internal standard during melatonin measurement in plasma samples<smiles>COc1ccc2[nH]cc(CCN)c2c1</smiles>

\section{Enzyme-linked immunoassay}

A variety of ELISAs for melatonin have also been reported that employ antisera identical to those used in the RIA described above. One such immunoassay employed melatonin-hemisuccinate-human serum albumin absorbed on polystyrene spheres, with the melatonin competing for a fixed amount of peroxidase labeled $\operatorname{IgG}$ antibody to melatonin [111]. This method had a detection limit of 22 fmol per tube and therefore required extraction. A competitive solid phase ELISA for human and rat serum and rat pineal gland has been described and validated using microtiter plates that has a much lower detection limit (1.0 fmol per well) as well as precision comparable with other methods and that can be applied without extraction to rat serum [112]. An improved version of this assay with a

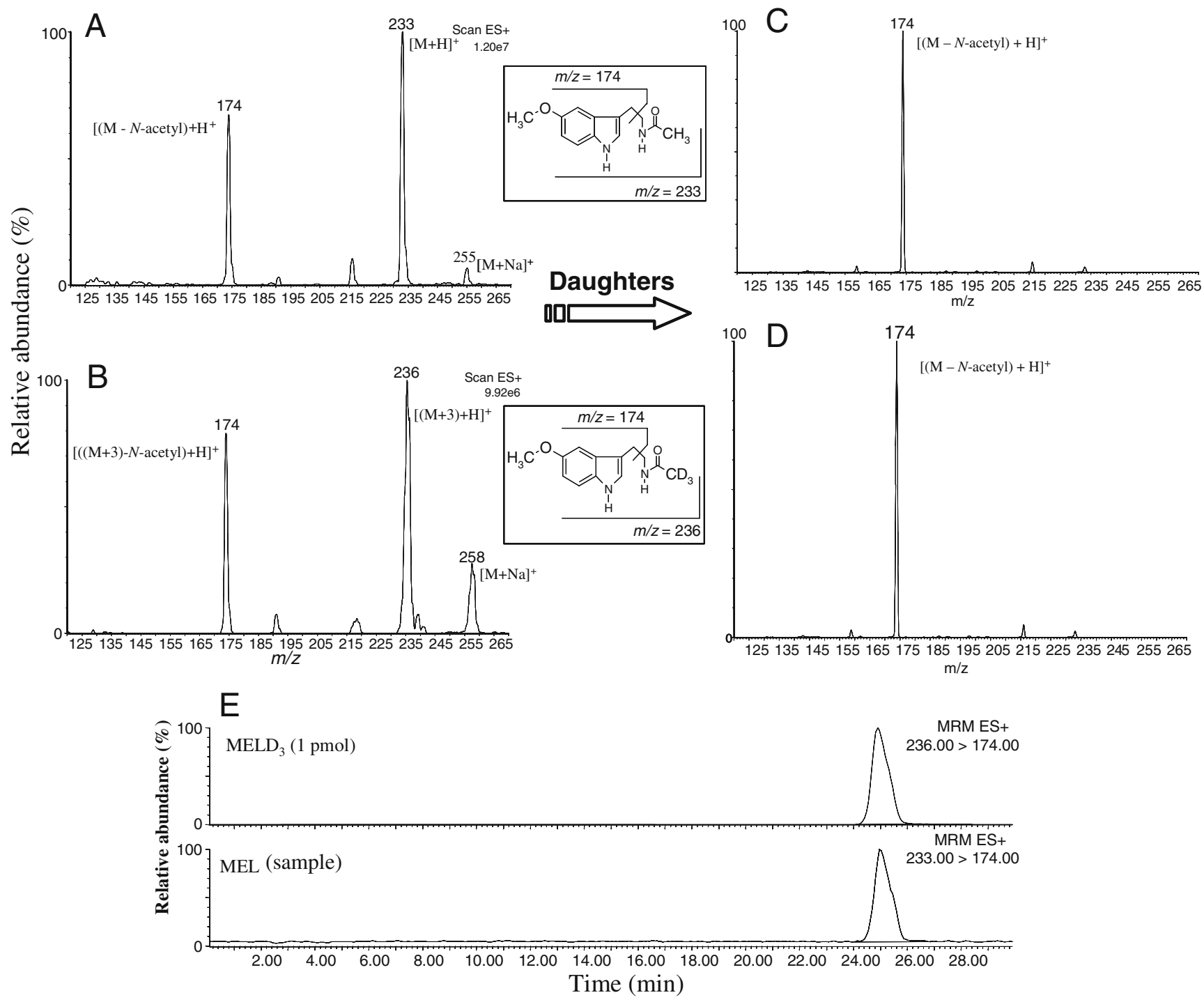

Fig. 3 Full mass scan spectra of melatonin (a) and deuterated melatonin (b) in the ESI+ mode, and their respective daughters (c and d) after fragmentation in the collision cell of the mass spectrometer. e A chromatogram of melatonin from a human plasma sample (MEL) and deuterated melatonin $\left(\mathrm{MELD}_{3}\right)$ as internal standard by HPLC-MS/MS 
shorter incubation time was subsequently reported [113]. A comparative study of an RIA and a commercial ELISA reported that the ELISA required a purification step to be valid when applied to human serum, a step that was not part of the procedure recommended by the manufacturer [114]. With the extraction step, the assay had distinct advantages, Enzyme assays have major advantages in that the enzyme conjugate is stable, is more convenient than ${ }^{3} \mathrm{H}$ or ${ }^{125} \mathrm{I}$ and present no problem with disposal of radioactive waste. Furthermore if microtiter plates are used centrifugation is not necessary. Although not an enzyme immunoassay, it is of interest that a time resolved fluoroimmunassay has also been described [115]. An enzyme immunoassay for 6sulfatoxymelatonin has been reported [116], and commercial kits are available.

HPLC coupled to electrochemical and fluorescence detection

In many studies, RIA methodology has been replaced by HPLC with electrochemical and fluorescence detection for melatonin evaluation, due to its great sensitivity and specificity [117]. However, this procedure is more adequate for melatonin alone, and not for mixtures of several indoles, such as serotonin and tryptamine among others, that can cause disruptions in the assay. For example, serotonin/ melatonin ratio is higher than 100 in rat pineal. This high ratio can cause disturbances in chromatographic separations that can make melatonin detection difficult, and thus requires a good procedure for melatonin extraction. However, the avoidance of partial coelution with other indoles is mostly a matter of the art of chromatography. In our work we have been able to detect melatonin with great accuracy in blood plasma after simple dichlorometane extraction as described above, and using an HPLC system connected to electrochemical detection. Figure 1 shows a chromatogram of melatonin detection in human plasma by this procedure. Good peak separation was achieved by using a LC-18 column and $50 \mathrm{mM}$ sodium acetate$100 \mathrm{mM}$ acetic acid (pH 4.3), $0.1 \mathrm{mM} \mathrm{Na}_{2}$-EDTA, and acetonitrile $(75: 25, \mathrm{v} / \mathrm{v})$ as mobile phase pumped isocratically at $1 \mathrm{ml} / \mathrm{min}$.

Harumi et al. [69] also successfully determined melatonin by HPLC with electrochemical detection, with very clear peak separation for different indoleamines among melatonin. However, the sensitivity of this procedure depends on the model of electrochemical cell. Amperometric-based electrochemical cells are generally less sensitive than coulometric cells, so that the adequate potential should be previously optimized by the construction of hydrodynamic voltammograms. With our coulometric electrochemical system, the best melatonin signal is obtained at $600 \mathrm{mV}$. Sensitivity can be also greater with coulometric electrochemical detectors such as the ESA coulochem III model (ESA, Bedford, MA, USA), which uses porous electrochemical cells that allow greater accuracy in melatonin peak resolution. Harumi et al. reported the use of a higher potential, $900 \mathrm{mV}$, for good melatonin signal with their graphite carbon working electrode, and even so they detected melatonin at very low levels [69]. Rizzo et al. [66] also used $900 \mathrm{mV}$ for melatonin detection with an amperometric electrochemical detector.

With respect of fluorescence detection, some highly sensitive methodologies have been reported for melatonin detection at the femtomole level [118-120]. Melatonin can be separated on a C18 column by using $75 \mathrm{mM}$ sodium acetate $\mathrm{pH} 5.0$ and acetonitrile $(72: 28, \mathrm{v} / \mathrm{v})$ as the mobile phase pumped isocratically at $1.0 \mathrm{ml} / \mathrm{min}$, and directly detected by setting up the fluorescence detector at an excitation wavelength of $275 \mathrm{~nm}$ and an emission wavelength of $345 \mathrm{~nm}$ [66]. Nevertheless, in some cases in which melatonin concentration is very low, derivatization is recommended to enhance the melatonin signal [118]. An oxidation procedure that can enhance melatonin fluorescence by 6.8 times (allowing its determination at attomole levels) has been described using biological samples [73] Melatonin was oxidized to a new fluorescent compound with sodium carbonate and hydrogen peroxide. However, precautions should be taken when using this kind of approach, because other components in the biological sample may lead to the generation of fluorophores, which in turn could interfere with the determination of the correct level, thus preventing method specificity [73].

In any case, care with sample preparation can improve the melatonin signal. Prepurification of melatonin as described before will decrease chromatogram noise and avoid the coelution of melatonin with other compounds that can interfere with melatonin peaks. Generally, the use of fluorescence techniques are affected not only by co-elution with other fluorescent compounds in the sample, but also by the presence of quenchers. This should not be underrated since the majority of aromates absorb around the excitation maximum of melatonin. Therefore, samples should be tested in advance for quenching by adding known amounts of melatonin.

\section{Mass spectrometry}

The GC-MS technique is very sensitive and offers more specificity than HPLC with electrochemical or fluorescence detectors; however, a difficulty with this technique is the need of derivatization, and thus it has been gradually substituted by liquid chromatography-mass spectrometry procedures. Thus, alternative HPLC-MS methods appropriate for use in biological issues have been developed [119, 
121-123]. However, this approach is limited by the need of adequate internal standards. Yang et al. described their methodology which used acetyltryptamine as the internal standard [119]; however, several factors make this approach less than ideal. It is appropriate to use a labeled internal standard whose structure is the same of the analyte except for the mass difference. The addition of an isotopically labeled internal standard prior to the analysis improves the method's confidence level.

Another analytical method has been developed which uses column-switching semi-microcolumn liquid chromatography/mass spectrometry and selected ion monitoring (SIM) for detecting endogenous melatonin in human saliva. In the relevant study melatonin was monitored based on its fragment ion at $\mathrm{m} / \mathrm{z} 174$ by in-source dissociation and using deuterated melatonin as the internal standard, and a detection limit of 10 fmol was obtained [74]. The main limitation of this methodology is the use of the SIM mode to detect the ions generated in the probe, which does not imply an absolute specificity. Yet, Eriksson et al. [123] reported a method for the determination of melatonin in human saliva by HPLC-MS/MS, using 7-D-melatonin as internal standard. The limit of detection was $1.05 \mathrm{pg} / \mathrm{ml}$ and the limit of quantification was $3.0 \mathrm{pg} / \mathrm{ml}$. One of us has reported the development of a new HPLC-MS/MS assay with electrospray ionization (ESI) to quantitatively determine melatonin and also its degradation product $N^{1}$-acetyl$N^{2}$-formyl-5-methoxykynuramine with high sensitivity and specificity [122]. A stable isotopic internal standard melatonin- $\mathrm{D}_{3}$ (deuterated melatonin) was easily synthesized by the reaction of 5-methoxytryptamine with deuterated acetyl chloride $\left(\mathrm{CD}_{3} \mathrm{COCl}\right)$ (Fig. 2).

The predominant ion $[\mathrm{M}+\mathrm{H}]^{+}$in the full scan mass spectra of melatonin, and melatonin- $\mathrm{D}_{3}$ were located (Fig. 3a-b). The fragments generated in collision-induced dissociation chamber revealed a predominant fragment at $m / z=174$ for melatonin and melatonin- $\mathrm{D}_{3}$ (loss of the $N$ acetyl group) (Fig. 3c-d). The $m / z$ transitions from 233 to 174 (melatonin) and from 236 to 174 (melatonin- $\mathrm{D}_{3}$ ) were therefore chosen for the Multiple Reaction Monitoring (MRM) detection experiments, which ensured a higher specificity and an accurate quantification of melatonin in human plasma (Fig. 3e). A chromatogram of melatonin and deuterated-melatonin is depicted in Fig. 4.

\section{Other techniques}

Some laboratories have taken and developed capillary electrophoresis (CE) for the separation and determination of melatonin in blood plasma [124-126] and in pineal gland $[127,128]$. Detection of analyte was performed with a UV and fluorescence [124-126, 129] or electrochemical detector $[127,128]$. The detection limit of melatonin with $\mathrm{CE}$ is comparable with the data obtained by HPLC methods reported previously. Recently, for the separation of melatonin from related compounds, CE with micellar electrokinetic chromatography was applied [125, 126, 128, 129]. This technique permitted the effective separation of melatonin and its precursors or metabolites. Sodium dodecyl sulfate is used to produce a pseudostationary phase.

\section{Conclusions}

The most common methods for determination of melatonin in blood or saliva are RIAs and ELISAs, and several commercial kits are now available for these assays. They are convenient to use, especially the enzyme based assays, but of the possibility of cross-reactions, and nonspecific effects must be considered. This is important because of the very low levels of melatonin that are to be measured. These potential problems can be reduced by determining when extraction is necessary and by comparing the results obtained with other established methods. It is expected that these methods will continue to improve and that enzyme assays will continue to gain ground for routine measurements of melatonin in blood and saliva.

Acknowledgments Part of this work (Paolo Di Mascio) was supported by the Brazilian research funding institutions FAPESP (Fundação de Amparo à Pesquisa do Estado de São Paulo), CNPq (Conselho Nacional para o Desenvolvimento Científico e Tecnológico), CAPES (Coordenação de Aperfeiçoamento de Pessoal de Nível Superior), L'ORÉAL-UNESCO for Women in Science (S.M. Fellow) and The John Simon Memorial Guggenheim Foundation (P.D.M. Fellow), and INCT de Processos Redox em Biomedicina - Redoxoma.

D.P.C. is a Research Career Awardee from the Argentine National Research Council (CONICET), Argentina.

Conflicts of interest S.R. Pandi-Perumal is a stockholder and the President and Chief Executive Officer of Somnogen Inc., a New York Corporation. He declared no competing interests that might be perceived to influence the content of this article.

Disclosures All remaining authors declare that they have no proprietary, financial, professional, nor any other personal interest of any nature or kind in any product or services and/or company that could be construed or considered to be a potential conflict of interest that might have influenced the views expressed in this manuscript.

\section{References}

1. Cardinali DP, Rosner JM (1971) Metabolism of serotonin by the rat retina "in vitro.". J Neurochem 18:1769-1770

2. Tosini G, Menaker M (1998) The clock in the mouse retina: melatonin synthesis and photoreceptor degeneration. Brain Res 789:221-228

3. Liu C, Fukuhara C, Wessel JH III, Iuvone PM, Tosini G (2004) Localization of Aa-nat mRNA in the rat retina by fluorescence in 
situ hybridization and laser capture microdissection. Cell Tissue Res 315:197-201

4. Conti A, Conconi S, Hertens E, Skwarlo-Sonta K, Markowska M, Maestroni JM (2000) Evidence for melatonin synthesis in mouse and human bone marrow cells. J Pineal Res 28:193-202

5. Champier J, Claustrat B, Besancon R, Eymin C, Killer C, Jouvet A, Chamba G, Fevre-Montange M (1997) Evidence for tryptophan hydroxylase and hydroxy-indol- $O$-methyl-transferase mRNAs in human blood platelets. Life Sci 60:2191-2197

6. Bubenik GA (2002) Gastrointestinal melatonin: localization, function, and clinical relevance. Dig Dis Sci 47:2336-2348

7. Slominski A, Fischer TW, Zmijewski MA, Wortsman J, Semak I, Zbytek B, Slominski RM, Tobin DJ (2005) On the role of melatonin in skin physiology and pathology. Endocr 27:137-148

8. Carrillo-Vico A, Calvo JR, Abreu P, Lardone PJ, Garcia-Maurino S, Reiter RJ, Guerrero JM (2004) Evidence of melatonin synthesis by human lymphocytes and its physiological significance: possible role as intracrine, autocrine, and/or paracrine substance. FASEB J 18:537-539

9. Dubocovich ML, Markowska M (2005) Functional $\mathrm{MT}_{1}$ and $\mathrm{MT}_{2}$ melatonin receptors in mammals. Endocr 27:101-110

10. Pandi-Perumal SR, Trakht I, Srinivasan V, Spence DW, Maestroni GJM, Zisapel N, Cardinali DP (2008) Physiological effects of melatonin: role of melatonin receptors and signal transduction pathways. Prog Neurobiol 185:335-353

11. Reiter RJ, Tan DX, Manchester LC, Paredes SD, Mayo JC, Sainz RM (2009) Melatonin and reproduction revisited. Biol Reprod $81: 445-456$

12. Lewy AJ, Emens J, Jackman A, Yuhas K (2006) Circadian uses of melatonin in humans. Chronobiol Int 23:403-412

13. Arendt J (2006) Melatonin and human rhythms. Chronobiol Int 23:21-37

14. Carrillo-Vico A, Reiter RJ, Lardone PJ, Herrera JL, FernandezMontesinos R, Guerrero JM, Pozo D (2006) The modulatory role of melatonin on immune responsiveness. Curr Opin Investig Drugs 7:423-431

15. Reiter RJ, Tan DX, Manchester LC, Tamura H (2007) Melatonin defeats neurally-derived free radicals and reduces the associated neuromorphological and neurobehavioral damage. J Physiol Pharmacol 58(Suppl 6):5-22

16. Reiter RJ, Paredes SD, Manchester LC, Tan DX (2009) Reducing oxidative/nitrosative stress: a newly-discovered genre for melatonin. Crit Rev Biochem Mol Biol 44:175-200

17. de Almeida EA, Martinez GR, Klitzke CF, de Medeiros MHG, Di Mascio P (2003) Oxidation of melatonin by singlet molecular oxygen produces $N^{1}$-acetyl- $N^{2}$-formyl-5-methoxykynurenine. J Pineal Res 35:131-137

18. Hardeland R, Tan DX, Reiter RJ (2009) Kynuramines, metabolites of melatonin and other indoles: the resurrection of an almost forgotten class of biogenic amines. J Pineal Res 47:109-116

19. Onuki J, Almeida EA, Medeiros MHG, Di Mascio P (2005) Inhibition of 5-aminolevulinic acid-induced DNA damage by melatonin, $N^{1}$-acetyl- $N^{2}$-formyl-5-methoxykynurenine, quercetin or resveratrol. J Pineal Res 38:107-115

20. Hardeland R (2009) Melatonin: signaling mechanisms of a pleiotropic agent. Biofactors 35:183-192

21. Doyle S, Menaker M (2007) Circadian photoreception in vertebrates. Cold Spring Harb Symp Quant Biol 72:499-508

22. Bentley GE (2001) Unraveling the enigma: the role of melatonin in seasonal processes in birds. Microsc Res Tech 53:63-71

23. Moore RY (2007) Suprachiasmatic nucleus in sleep-wake regulation. Sleep Med 8(Suppl 3):27-33

24. Goldman BD (2001) Mammalian photoperiodic system: formal properties and neuroendocrine mechanisms of photoperiodic time measurement. J Biol Rhythms 16:283-301
25. Cassone VM, Paulose JK, Whitfield-Rucker MG, Peters JL (2009) Time's arrow flies like a bird: two paradoxes for avian circadian biology. Gen Comp Endocrinol 163:109-116

26. Zawilska JB, Berezinska M, Lorenc A, Skene DJ, Nowak JZ (2004) Retinal illumination phase shifts the circadian rhythm of serotonin $\mathrm{N}$-acetyltransferase activity in the chicken pineal gland. Neurosci Lett 360:153-156

27. Csernus VJ (2006) The avian pineal gland. Chronobiol Int 23:329-339

28. Benloucif S, Burgess HJ, Klerman EB, Lewy AJ, Middleton B, Murphy PJ, Parry BL, Revell VL (2008) Measuring melatonin in humans. J Clin Sleep Med 4:66-69

29. Lewy AJ, Sack RL, Singer CM (1985) Immediate and delayed effects of bright light on human melatonin production: shifting "dawn" and "dusk" shifts the dim light melatonin onset (DLMO). Ann NY Acad Sci 453:253-259

30. Pandi-Perumal SR, Smits M, Spence W, Srinivasan V, Cardinali DP, Lowe AD, Kayumov L (2007) Dim light melatonin onset (DLMO): a tool for the analysis of circadian phase in human sleep and chronobiological disorders. Prog Neuropsychopharmacol Biol Psychiatry 31:1-11

31. Lagana A, Pardo-Martinez B, Marino A, Fago G, Bizzarri M (1995) Determination of serum total lipid and free $\mathrm{N}$ acetylneuraminic acid in genitourinary malignancies by fluorimetric high performance liquid chromatography. Relevance of free $\mathrm{N}$-acetylneuraminic acid as tumour marker. Clin Chim Acta 243:165-179

32. Machida M, Dubousset J, Yamada T, Kimura J (2009) Serum melatonin levels in adolescent idiopathic scoliosis prediction and prevention for curve progression - a prospective study. J Pineal Res 46:344-348

33. Bartness TJ, Goldman BD (1989) Mammalian pineal melatonin: a clock for all seasons. Experientia 45:939-945

34. Ho AK, Grota LJ, Brown GM (1984) Relationship between pineal $N$-acetyltransferase activity, pineal melatonin and serum melatonin in rats under different lighting conditions. Neuroendocrinology 39:465-470

35. Ribelayga C, Pevet P, Simonneaux V (2000) HIOMT drives the photoperiodic changes in the amplitude of the melatonin peak of the Siberian hamster. Am J Physiol Regul Integr Comp Physiol 278:R1339-R1345

36. Vivien-Roels B, Pevet P, Masson-Pevet M, Canguilhem B (1992) Seasonal variations in the daily rhythm of pineal gland and/or circulating melatonin and 5-methoxytryptophol concentrations in the European hamster, Cricetus cricetus. Gen Comp Endocrinol $86: 239-247$

37. Ueno-Towatari T, Norimatsu K, Blazejczyk K, Tokura H, Morita $T$ (2007) Seasonal variations of melatonin secretion in young females under natural and artificial light conditions in Fukuoka, Japan. J Physiol Anthropol 26:209-215

38. Morera AL, Abreu P (2006) Seasonality of psychopathology and circannual melatonin rhythm. J Pineal Res 41:279-283

39. Lewy AJ, Wehr TA, Goodwin FK, Newsome DA, Markey SP (1980) Light suppresses melatonin secretion in humans. Science 210:1267-1269

40. Stevens RG, Blask DE, Brainard GC, Hansen J, Lockley SW, Provencio I, Rea MS, Reinlib L (2007) Meeting report: the role of environmental lighting and circadian disruption in cancer and other diseases. Environ Health Perspect 115:1357-1362

41. Schomerus C, Korf HW, Laedtke E, Weller JL, Klein DC (2000) Selective adrenergic/cyclic AMP-dependent switch-off of proteasomal proteolysis alone switches on neural signal transduction: an example from the pineal gland. J Neurochem 75:2123-2132

42. Ganguly S, Gastel JA, Weller JL, Schwartz C, Jaffe H, Namboodiri MA, Coon SL, Hickman AB, Rollag M, Obsil T, Beauverger P, Ferry G, Boutin JA, Klein DC (2001) Role of a 
pineal cAMP-operated arylalkylamine $N$-acetyltransferase/14-33-binding switch in melatonin synthesis. Proc Natl Acad Sci USA 98:8083-8088

43. Grof E, Grof P, Brown GM, Arato M, Lane J (1985) Investigations of melatonin secretion in man. Prog Neuropsychopharmacol Biol Psychiatry 9:609-612

44. Waldhauser F, Dietzel M (1985) Daily and annual rhythms in human melatonin secretion: role in puberty control. Ann NY Acad Sci 453:205-214

45. Lerchl A, Partsch CJ (1994) Reliable analysis of individual human melatonin profiles by complex cosinor analysis. J Pineal Res 16:85-90

46. Koller M, Harma M, Laitinen JT, Kundi M, Piegler B, Haider M (1994) Different patterns of light exposure in relation to melatonin and cortisol rhythms and sleep of night workers. J Pineal Res 16:127-135

47. Brown GM, Young SN, Gauthier S, Tsui H, Grota LJ (1979) Melatonin in human cerebrospinal fluid in daytime; its origin and variation with age. Life Sci 25:929-936

48. Karasek M, Reiter RJ (2002) Melatonin and aging. Neuro Endocrinol Lett 23(Suppl 1):14-16

49. Girotti L, Lago M, Yanovsky O, Carbajales J, Elizari M, Brusco LI, Cardinali DP (2000) Low urinary 6-sulphatoxymelatonin levels in patients with coronary artery disease. J Pineal Res 29:138-142

50. Girotti L, Lago M, Ianovsky O, Elizari M, Dini A, Pérez Lloret S, Albornoz LE, Cardinali DP (2003) Low urinary 6sulphatoxymelatonin levels in patients with severe congestive heart failure. Endocr 22:245-248

51. Yaprak M, Altun A, Vardar A, Aktoz M, Ciftci S, Ozbay G (2003) Decreased nocturnal synthesis of melatonin in patients with coronary artery disease. Int J Cardiol 89:103-107

52. Peschke E (2008) Melatonin, endocrine pancreas and diabetes. J Pineal Res 44:26-40

53. Griefahn B, Brode P, Remer T, Blaszkewicz M (2003) Excretion of 6-hydroxymelatonin sulfate (6-OHMS) in siblings during childhood and adolescence. Neuroendocrinology 78:241-243

54. Barber SG, Smith JA, Hughes RC (1978) Melatonin as a tumour marker in a patient with pineal tumour. BMJ 2:328

55. Kennaway DJ, McCulloch G, Matthews CD, Seamark RF (1979) Plasma melatonin, luteinizing hormone, follicle-stimulating hormone, prolactin, and corticoids in two patients with pinealoma. J Clin Endocrinol Metab 49:144-145

56. Miles A, Tidmarsh SF, Philbrick D, Shaw DM (1985) Diagnostic potential of melatonin analysis in pineal tumors. N Engl J Med 313:329-330

57. Grimoldi N, Tomei G, Stankov B, Lucini V, Masini B, Caputo V, Repetti ML, Lazzarini G, Gaini SM, Lucarini C, Fraschini F, Villani R (1998) Neuroendocrine, immunohistochemical, and ultrastructural study of pineal region tumors. J Pineal Res $25: 147-158$

58. Leston J, Mottolese C, Champier J, Jouvet A, Brun J, Sindou M, Chazot G, Claustrat B, Fevre-Montange M (2009) Contribution of the daily melatonin profile to diagnosis of tumors of the pineal region. J Neurooncol 93:387-394

59. Vorkapic P, Waldhauser F, Bruckner R, Biegelmayer C, Schmidbauer M, Pendl G (1987) Serum melatonin levels: a new neurodiagnostic tool in pineal region tumors? Neurosurgery 21:817-824

60. Kocher L, Brun J, Borson-Chazot F, Gonnaud PM, Claustrat B (2006) Increased REM sleep associated with melatonin deficiency after pinealectomy: a case study. Chronobiol Int 23:889-901

61. Chazot G, Claustrat B, Broussolle E, Lapras C (1991) Headache and depression: recurrent symptoms in adult pinealectomized patient. In: Nappi G, Bono G, Sandrini G, Martignoni E, Micieli
G (eds) Headache and depression. Raven Press, New York, pp 299-303

62. Lehmann ED, Cockerell OC, Rudge P (1996) Somnolence associated with melatonin deficiency after pinealectomy. Lancet 347:323

63. Muller HL, Handwerker G, Wollny B, Faldum A, Sorensen N (2002) Melatonin secretion and increased daytime sleepiness in childhood craniopharyngioma patients. J Clin Endocrinol Metab 87:3993-3996

64. Muller HL, Handwerker G, Gebhardt U, Faldum A, Emser A, Kolb R, Sorensen N (2006) Melatonin treatment in obese patients with childhood craniopharyngioma and increased daytime sleepiness. Cancer Causes Control 17:583-589

65. Lipton J, Megerian JT, Kothare SV, Cho YJ, Shanahan T, Chart H, Ferber R, Adler-Golden L, Cohen LE, Czeisler CA, Pomeroy SL (2009) Melatonin deficiency and disrupted circadian rhythms in pediatric survivors of craniopharyngioma. Neurology 73:323-325

66. Rizzo V, Porta C, Moroni M, Scoglio E, Moratti R (2002) Determination of free and total (free plus protein-bound) melatonin in plasma and cerebrospinal fluid by highperformance liquid chromatography with fluorescence detection. J Chromatogr B Anal Technol Biomed Life Sci 774:17-24

67. Harumi T, Matsushima S (2000) Separation and assay methods for melatonin and its precursors. J Chromatogr B Biomed Sci Appl 747:95-110

68. Sieghart W, Ronca E, Drexler G, Karall S (1987) Improved radioimmunoassay of melatonin in serum. Clin Chem 33:604 605

69. Harumi T, Akutsu H, Matsushima S (1996) Simultaneous determination of serotonin, $\mathrm{N}$-acetylserotonin and melatonin in the pineal gland of the juvenile golden hamster by highperformance liquid chromatography with electrochemical detection. J Chromatogr B Biomed Appl 675:152-156

70. Degen PH, DoAmaral JR, Barchas JD (1972) A gas-liquid chromatographic assay of melatonin and indoleamines using heptafluorobutyryl derivatives. Anal Biochem 45:634-644

71. Covaci A, Doneanu C, Aboul-Enein HY, Schepens P (1999) Determination of melatonin in pharmaceutical formulations and human plasma by gas chromatography-electron impact mass spectrometry. Biomed Chromatogr 13:431-436

72. Bechgaard E, Lindhardt K, Martinsen L (1998) Highperformance liquid chromatographic analysis of melatonin in human plasma and rabbit serum with on-line column enrichment. J Chromatogr B Biomed Sci Appl 712:177-181

73. Tomita T, Hamase K, Hayashi H, Fukuda H, Hirano J, Zaitsu K (2003) Determination of endogenous melatonin in the individual pineal glands of inbred mice using precolumn oxidation reversed-phase micro-high-performance liquid chromatography. Anal Biochem 316:154-161

74. Rolčik J, Lenobel R, Siglerova V, Strnad M (2002) Isolation of melatonin by immunoaffinity chromatography. J Chromatogr B Anal Technol Biomed Life Sci 775:9-15

75. Grota LJ, Snieckus V, de Silva SO, Tsui HW, Holloway WR, Lewy AJ, Brown GM (1981) Radioimmunoassay of melatonin in rat serum. Prog Neuropsychopharmacol 5:523-526

76. Lemaitre BJ, Hartmann L (1980) Preparation of anti-melatonin antibodies and antigenic properties of the molecule. J Immunol Methods 32:339-347

77. Di WL, Kadva A, Djahanbakhch O, Silman R (1998) Radioimmunoassay of bound and free melatonin in plasma. Clin Chem 44:304-310

78. Grota LJ, Snieckus V, de Silva SO, Brown GM (1983) Antibodies to indolealkylamines II: site of conjugation of melatonin to protein using formaldehyde. Can J Biochem Cell Biol 61:1096-1101 
79. Pang SF, Brown GM, Grota LJ, Chambers JW, Rodman RL (1977) Determination of $\mathrm{N}$-acetylserotonin and melatonin activities in the pineal gland, retina, harderian gland, brain and serum of rats and chickens. Neuroendocrinology 23:1-13

80. Bubenik GA, Brown GM, Grota LJ (1976) Immunohistochemical localization of melatonin in the rat Harderian gland. J Histochem Cytochem 24:1173-1177

81. Yang T, Wang J, Qu L, Zhong P, Yuan Y (2006) Preparation and identification of anti-melatonin monoclonal antibodies. J Pineal Res 40:350-354

82. Soukhtanloo M, Ansari M, Paknejad M, Parizadeh MR, Rasaee MJ (2008) Preparation and characterization of monoclonal antibody against melatonin. Hybridoma 27:205-209

83. de Silva SO, Snieckus V (1978) Indole- $N$-alkylation of tryptamines via dianion and phtalimido intermediates. New potential indolealkylamine hapten. Can J Chem 56:1621-1628

84. Kawashima K, Nagakura A, Wurzburger RJ, Spector S (1984) Melatonin in serum and the pineal of spontaneously hypertensive rats. Clin Exp Hypertens A 6:1517-1528

85. Blair IA, Seaborn CJ (1979) The synthesis of melatonin antigens. Aust J Chem 32:399-403

86. Kennaway DJ, Gilmore TA, Seamark RF (1982) Effects of melatonin implants on the circadian rhythm of plasma melatonin and prolactin in sheep. Endocrinology 110:2186-2188

87. Manz B, Seidel A, Alexander H, Vollrath L, Wagner B, Zimmermann G, Wiedemann K, Pollow K (1989) Development and validation of a radioimmunoassay for serum melatonin. $\mathrm{J}$ Clin Chem Clin Biochem 27:797-802

88. Wilkinson M, Arendt J, Bradtke J, de Ziegler D (1977) Determination of a dark-induced increase of pineal $\mathrm{N}$-acetyl transferase activity and simultaneous radioimmunoassay of melatonin in pineal, serum and pituitary tissue of the male rat. J Endocrinol 72:243-244

89. Vakkuri O, Leppaluoto J, Vuolteenaho O (1984) Development and validation of a melatonin radioimmunoassay using radioiodinated melatonin as tracer. Acta Endocrinol 106:152-157

90. Rollag MD, Niswender GD (1976) Radioimmunoassay of serum concentrations of melatonin in sheep exposed to different lighting regimens. Endocrinology 98:482-489

91. Levine L, Riceberg LJ (1975) Radioimmunoassay for melatonin. Res Commun Chem Pathol Pharmacol 10:693-702

92. Wurzburger RJ, Kawashima K, Miller RL, Spector S (1976) Determination of rat pineal gland melatonin content by a radioimmunoassay. Life Sci 18:867-877

93. Lynch HJ, Ozaki Y, Shakal D, Wurtman RJ (1975) Melatonin excretion of man and rats: effect of time of day, sleep, pinealectomy and food consumption. Int $\mathrm{J}$ Biometeorol 19:267-279

94. Grota LJ, Brown GM (1974) Antibodies to indolealkylamines: serotonin and melatonin. Can J Biochem 52:196-202

95. Kennaway DJ, Frith RG, Phillipou G, Matthews CD, Seamark RF (1977) A specific radioimmunoassay for melatonin in biological tissue and fluids and its validation by gas chromatography-mass spectrometry. Endocrinology 101:119127

96. Arendt J, Bojkowski C, Franey C, Wright J, Marks V (1985) Immunoassay of 6-hydroxymelatonin sulfate in human plasma and urine: abolition of the urinary 24-hour rhythm with atenolol. $\mathrm{J}$ Clin Endocrinol Metab 60:1166-1173

97. Fraser S, Cowen P, Franklin M, Franey C, Arendt J (1983) Direct radioimmunoassay for melatonin in plasma. Clin Chem 29:396397

98. English J, Middleton BA, Arendt J, Wirz-Justice A (1993) Rapid direct measurement of melatonin in saliva using an iodinated tracer and solid phase second antibody. Ann Clin Biochem 30 (4):415-416
99. Miles A, Philbrick D, Tidmarsh SF, Shaw DM (1985) Direct radioimmunoassay of melatonin in saliva. Clin Chem 31:14121413

100. Miles A, Philbrick DR, Grey JE (1989) Salivary melatonin estimation in assessment of pineal-gland function. Clin Chem 35:514-515

101. Vakkuri O (1985) Diurnal rhythm of melatonin in human saliva. Acta Physiol Scand 124:409-412

102. Lewy AJ, Sack RL (1989) The dim light melatonin onset as a marker for circadian phase position. Chronobiol Int 6:93-102

103. Leibenluft E, Feldman-Naim S, Turner EH, Schwartz PJ, Wehr TA (1996) Salivary and plasma measures of dim light melatonin onset (DLMO) in patients with rapid cycling bipolar disorder. Biol Psychiatry 40:731-735

104. Poeggeler B, Huether G (1992) Versatile one-tube scintillation proximity homogeneous radioimmunoassay of melatonin. Clin Chem 38:314-315

105. Markey SP, Higa S, Shih M, Danforth DN, Tamarkin L (1985) The correlation between human plasma melatonin levels and urinary 6hydroxymelatonin excretion. Clin Chim Acta 150:221-225

106. Nowak R, McMillen IC, Redman J, Short RV (1987) The correlation between serum and salivary melatonin concentrations and urinary 6-hydroxymelatonin sulphate excretion rates: two non-invasive techniques for monitoring human circadian rhythmicity. Clin Endocrinol 27:445-452

107. Cavallo A, Dolan LM (1996) 6-Hydroxymelatonin sulfate excretion in human puberty. J Pineal Res 21:225-230

108. Martin PR, Higa S, Burns RS, Tamarkin L, Ebert MH, Markey SP (1984) Decreased 6-hydroxymelatonin excretion in Korsakoff's psychosis. Neurology 34:966-968

109. John TM, Brown MC, Brown GM (1992) An oral melatonin replacement regimen that re-establishes the normal circadian levels of urinary 6-sulphatoxymelatonin in functionally pinealectomized rats. J Pineal Res 13:145-150

110. Fideleff HL, Boquete H, Fideleff G, Albornoz L, Pérez Lloret S, Suarez M, Esquifino AI, Honfi M, Cardinali DP (2006) Genderrelated differences in urinary 6-sulfatoxymelatonin levels in obese pubertal individuals. J Pineal Res 40:214-218

111. Ferrua B, Masseyeff R (1985) Immunoassay of melatonin with enzyme-labeled antibodies. J Immunoassay 6:79-94

112. Yie SM, Johansson E, Brown GM (1993) Competitive solidphase enzyme immunoassay for melatonin in human and rat serum and rat pineal gland. Clin Chem 39:2322-2325

113. Shavali S, Samejima M, Uchida K, Morita Y, Fukuda A (1999) Improved enzyme immunoassay method for melatonin: application to the determination of serum melatonin in rats, sheep, and humans. Clin Chem 45:690-692

114. Chegini S, Ehrhart-Hofmann B, Kaider A, Waldhauser F (1995) Direct enzyme-linked immunosorbent assay and a radioimmunoassay for melatonin compared. Clin Chem 41:381-386

115. Yamada H, Chiba H, Amano M, Iigo M, Iwata M (2002) Rainbow trout eyed-stage embryos demonstrate melatonin rhythms under light-dark conditions as measured by a newly developed time-resolved fluoroimmunoassay. Gen Comp Endocrinol 125:41-46

116. Peniston-Bird JF, Di WL, Street CA, Edwards R, Little JA, Silman RE (1996) An enzyme immunoassay for 6-sulphatoxymelatonin in human urine. J Pineal Res 20:51-56

117. Vitale AA, Ferrari CC, Aldana H, Affanni JM (1996) Highly sensitive method for the determination of melatonin by normalphase high-performance liquid chromatography with fluorometric detection. J Chromatogr B Biomed Appl 681:381-384

118. Iinuma F, Hamase K, Matsubayashi S, Takahashi M, Watanabe M, Zaitsu K (1999) Sensitive determination of melatonin by precolumn derivatization and reversed-phase high-performance liquid chromatography. J Chromatogr A 835:67-72 
119. Yang S, Zheng X, Xu Y, Zhou X (2002) Rapid determination of serum melatonin by ESI-MS-MS with direct sample injection. J Pharm Biomed Anal 30:781-790

120. Simonin G, Bru L, Lelievre E, Jeanniot JP, Bromet N, Walther B, Boursier-Neyret C (1999) Determination of melatonin in biological fluids in the presence of the melatonin agonist $\mathrm{S}$ 20098: comparison of immunological techniques and GC-MS methods. J Pharm Biomed Anal 21:591-601

121. Motoyama A, Kanda T, Namba R (2004) Direct determination of endogenous melatonin in human saliva by column-switching semi-microcolumn liquid chromatography/mass spectrometry with on-line analyte enrichment. Rapid Commun Mass Spectrom $18: 1250-1258$

122. de Almeida EA, Klitzke CF, Martinez GR, Medeiros MHG, Di Mascio P (2004) Synthesis of internal labeled standards of melatonin and its metabolite $N^{1}$-acetyl- $N^{2}$-formyl-5methoxykynurenin for their quantification using an on-line liquid chromatography-electrospray tandem mass spectrometry system. J Pineal Res 36:64-71

123. Eriksson K, Ostin A, Levin JO (2003) Quantification of melatonin in human saliva by liquid chromatography-tandem mass spectrometry using stable isotope dilution. J Chromatogr B Anal Technol Biomed Life Sci 794:115-123

124. Kim YO, Chung HJ, Chung ST, Kim JH, Park JH, Han SY, Kil KS, Cho DH (1999) Determination of melatonin in biological samples by capillary electrophoresis. J Chromatogr A 850:369374

125. Pobozy E, Michalski A, Sotowska-Brochocka J, Trojanowicz M (2005) Determination of melatonin and its precursors and metabolites using capillary electrophoresis with UV and fluorometric detection. J Sep Sci 28:2165-2172

126. Musijowski J, Pobozy E, Trojanowicz M (2006) On-line preconcentration techniques in determination of melatonin and its precursors/metabolites using micellar electrokinetic chromatography. J Chromatogr A 1104:337-345

127. Chen G, Cheng J, Ye J (2001) Application of a novel microinjector in the determination of indole derivatives in the rat pineal gland by capillary electrophoresis with electrochemical detection. Fresenius J Anal Chem 370:930-934

128. Wu X, Wu W, Zhang L, Xie Z, Qiu B, Chen G (2006) Micellar electrokinetic capillary chromatography for fast separation and sensitive determination of melatonin and related indoleamines using end-column amperometric detection. Electrophoresis 27:4230-4239

129. Hevia D, Botas C, Sainz RM, Quiros I, Blanco D, Tan DX, Gomez-Cordoves C, Mayo JC (2010) Development and validation of new methods for the determination of melatonin and its oxidative metabolites by high performance liquid chromatography and capillary electrophoresis, using multivariate optimization. J Chromatogr A 1217:1368-1374 